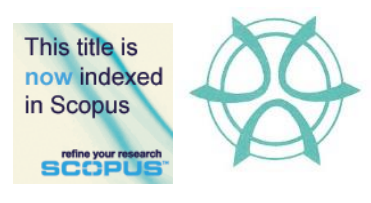

\title{
AN INITIATIVES-BASED FRAMEWORK FOR ASSESSING SMART CITY
}

\author{
Yasmin Mohd Adnan', Hasniyati Hamzah², Melasutra Md Dali ${ }^{3}$, Md Nasir Daud ${ }^{4}$ \\ \& Anuar Alias 5 \\ ${ }^{1,2,3,4,5}$ Centre for Sustainable Urban Planning \& Real Estate \\ Faculty of Built Environment \\ UNIVERSITY OF MALAYA
}

\begin{abstract}
Smart Cities have grown in prominence due to advancement in ICT and the new paradigm of sustainable city management and development. Whilst many authors have proposed guidelines and framework for Smart City implementation, less attention has been given to the assessment of Smart City performance. The mainstream Smart City assessment framework generally entails the quantitative assessment of factors, elements and initiatives categorised under the Smart City dimensions. However, this approach is problematic and impractical because it requires a large amount of different baseline data that is often at times unavailable due to various reasons. This paper describes an alternative framework for smart city assessment, one that is based on the modification of Giffinger's to make it amenable to leaner data. The proposed assessment framework was adopted to assess the smart city performances of Seoul, Singapore, and Iskandar Malaysia which were then compared. With the use of the framework for the performance assessment, the city that has performed better than the others is able to be identified.
\end{abstract}

Keywords: Smart city, assessment framework, dimensions, initiatives 
Yasmin Mohd Adnan, Hasniyati hamzah, Melasutra Md Dali, Md Nasir Daud \& Anuar Alias

An Initiative Based Assessment Framework for Smart City

\section{INTRODUCTION}

The Smart City concept has received increasing attention during the last decade along with the rapid technological advancement, whereby unleashing the 'smart' potentials of a city has been recognised as a strategy to maintain the city's relevance in an increasingly connected world. Malaysia has joined the smart city bandwagon with the recent move to declare and promote Iskandar Malaysia as the pioneer smart city in the country. Numerous studies have been undertaken on smart city assessment framework (see for instance Carli et.al. 2013; Neirotti et. al. 2014). They invariably work their frameworks from Giffinger et. al. (2007)'s original six dimensions. These dimensions are the Economy, People, Governance, Mobility, Environment and Living.

The need to measure smart city arises at least for two reasons: to be able to establish the smartness of a city in relation to the other cities and, more importantly, to identify smart features in which the city lags in order to target for improvement for the city. Unfortunately, the mainstream framework is quite problematic to use. The main challenge lies in meeting the requirements of the data it needs. This situation arises mainly because of the data requirements. Not only the process is tedious but can also be problematic given the nature of the data it requires. This is particularly when some of these data reside within private domain and is not released to the public, or that they are unavailable simply because they have yet to be collected.

This paper discusses an alternative framework for assessing city smartness performance, one that provides a more heuristic approach to such exercise. It intends to illustrate how this approach could offer a simpler computational methodology through lower qualitative requirement on input data for assessing the Smart City performance of three (3) Smart Cities, namely Seoul, Singapore and Iskandar Malaysia. The selection of the Smart Cities was guided by the aim to compare existing Smart City achievements in Malaysia with other Smart Cities in the neighbouring region. Whilst there are obvious socioeconomic, political, geographic and environmental differences, Malaysia has more in common with Korea and Singapore compared to Western countries. Although not involving a large number of countries, this paper involves an indepth examination of the three cities' Smart City initiatives and programmes against the cities' functions and prevailing institutional factors. In doing so, the study of the Smart City achievements would be more meaningful as it is framed against the context, rather than exists in a standalone framework.

\section{SMART CITY - A DEFINITION}

Although 'Smart City' has now become a term within the realm of sustainable development, the quest for a universal definition continues to present a challenge (Vanolo, 2014; Yanrong et al., 2014). Concepts such as intelligent cities, virtual cities, digital cities, information cities, wireless cities, future cities are often used 
PLANNING MALAYSIA

Sustainable Urban Development

interchangeably with 'Smart City'. In practice, the term 'Smart City' has been interpreted in various ways by the public and private sectors to suit their agenda (Yanrong et. al., 2014). The prevailing views of the definition tend to focus on the central role of technologies, specifically information and communications technology (ICT) and smart computing, in shaping cities' liveability and sustainability. The smart city is then regarded as an urban laboratory, an urban innovation ecosystem, a living lab, an agent of change (Schaffers et. al., 2012). In an alternative view, a city is considered 'smart' when investments in human and social capital and traditional (transportation) and modern (ICT-based) infrastructure fuel sustainable economic growth and a high quality of life, with a wise management of natural resources, through participatory government (Caragliu et. al., 2009).

While defining smart city remains an unresolved issue, researchers seem to go along well with the idea of six dimensions to a smart city, as propounded by Giffinger. According to the idea, the six smart city dimensions are smart economy, smart people, smart governance, smart mobility, smart environment and smart living. These dimensions were constituted as indicators for city smartness, to indicate the extent to which a city is smart. To develop the instrument to gauge the smartness of a city, Giffinger proceeded to construct criteria and indicators based on these six dimensions and, in the process, derived seventy four (74) assessment indicators. The reader is referred to Giffinger et. al. (2007) for a fuller description. Giffinger's model has exerted major influence in this domain of enquiry to be regarded as the mainstream framework, with it having received more than 400 citations.

\section{THE 'MAINSTREAM' SMART CITY ASSESSMENT FRAMEWORK}

The mainstream assessment framework by Giffinger involves collecting, collating and analysing quantitative data for each smart city dimension. For example, under smart environment, the required data includes $\mathrm{CO}_{2}$ emission, hours of sunshine and level of particulate matter. A number of authors have adopted this approach including Carli et. al. (2013), Lombardi (2012) and Neirotti et. al. (2014).

The mainstream approach above requires the availability of rich datasets, whether from the authorities or the private sectors. This may work well with cities in developed countries but can be a major problem elsewhere, particularly in less developed economies. For many cities, there is no data to support analysis on a significant portion of Giffinger's assessment indicators. Data is not available simply because no authoritative body or agency is made responsible to collect such information so far, or that such information cannot be accessed for being private and confidential. As this study has discovered, the constraint on data severely limits the utility of the mainstream approach for assessing cities for smartness comparison, even when the cities lie within the same region. The 
Yasmin Mohd Adnan, Hasniyati hamzah, Melasutra Md Dali, Md Nasir Daud \& Anuar Alias

An Initiative Based Assessment Framework for Smart City

problem had triggered this initiative to explore an alternative assessment framework, one that exercises flexibility with the data, relying on what information one can get.

\section{PROPOSED ALTERNATIVE SMART CITY ASSESSMENT FRAMEWORK}

To overcome the restrictiveness inherent in the mainstream framework above, an alternative approach is proposed here with a heuristic outlook to offer. Rather than work with fixed indicators, this approach examines initiatives undertaken to make a city smart and proceeds to analyse the initiatives qualitatively. Data on the initiatives is extracted from government reports, official websites and government online publications. This is followed by field visits to the cities involved to conduct key informant interviews with stakeholders (city officials, urban research and management organisations, and researchers) as well as to validate information that has been secured through third party sources. The visits also enable documentary evidence to be gathered and ground observation to be made. The aim is to ascertain the smart city initiatives practiced by each city and to observe the extent to which the initiatives have been practiced in relation to the score table which this study developed based on smart city descriptors (see Table $1)$.

\section{Smart City Descriptors Score Table}

Drawing from the factors under each dimension from Giffinger's and Iskandar Malaysia's models, the measurement and description of the initiatives identified under each dimension are developed. A summary of the descriptors is shown in Table 1 (Score Table) below. By using these descriptors, a comparative review is made on the smart city initiatives through the achievement level identified through the descriptors for the selected cities: Seoul, Singapore and Iskandar Malaysia. The achievement levels were divided into four, namely, Basic, High, Advanced and State-of-the Art. A heuristic analysis informed by the initiatives and fieldwork observation then guided the assignment of levels for each smart dimension for each city. A visual depiction of the results can then be represented by a radar diagram showing levels of achievement of the Smart Dimensions between the three (3) cities.

\section{Assessing Smart City}

Through this exercise, the cities' smartness categories by dimension are attained. To be capable of a quantitative treatment, the smartness category is then associated with numerical value, putting the achievement of the smartness category on a scale of 1 to 4 with each scale corresponding to each category. An analysis of Smart City initiatives between the selected cities was undertaken. 
PLANNING MALAYSIA

Sustainable Urban Development

Table 1: The descriptors for the level of achievement under each dimension

\begin{tabular}{|c|c|c|}
\hline $\begin{array}{l}\text { Smart } \\
\text { dimension }\end{array}$ & & City's level of provision \\
\hline \multirow[t]{4}{*}{ Smart Economy } & Basic (1) & $\begin{array}{l}\text { Facilitating local economic activities (infrastructure, } \\
\text { facilities, economic support system) }\end{array}$ \\
\hline & Medium (2) & Economic growth and value creation \\
\hline & Advance (3) & Innovative economic growth \\
\hline & State of the Art (4) & Integrated economic hub \\
\hline \multirow[t]{4}{*}{ Smart People } & Basic (1) & $\begin{array}{l}\text { Provision and accessibility to basic level of infrastructure } \\
\text { and programmes for the training and education towards } \\
\text { enhancement of skills and knowledge }\end{array}$ \\
\hline & Medium (2) & $\begin{array}{l}\text { Provision and creation of elaborate human capital } \\
\text { improvement environment with physical and non- } \\
\text { physical platforms for the advancement of knowledge, } \\
\text { skills and sharing ideals }\end{array}$ \\
\hline & Advance (3) & $\begin{array}{l}\text { Creation of a conducive ecosystem that attracts and } \\
\text { develops human capital through physical and non- } \\
\text { physical platform with advanced technological features } \\
\text { for the advancement of knowledge, skills and sharing } \\
\text { ideals towards a caring and open mind set }\end{array}$ \\
\hline & State of the Art (4) & $\begin{array}{l}\text { Development and creation of a conducive ecosystem that } \\
\text { attracts and develops human capital through the adoption } \\
\text { of state of the art ICT and technology driven educational } \\
\text { and training towards the cosmopolitanism, caring and } \\
\text { open mind set }\end{array}$ \\
\hline \multirow[t]{4}{*}{ Smart Governance } & Basic (1) & Provision of basic public and social services \\
\hline & Medium (2) & Public participation in decision-making \\
\hline & Advance (3) & Public-private partnership \\
\hline & State of the Art (4) & $\begin{array}{l}\text { Fully transparent government with ICT that provides } \\
\text { real-time policy conveyance and input }\end{array}$ \\
\hline \multirow[t]{4}{*}{ Smart Mobility } & Basic (1) & Basic transportation and connectivity to ease movement \\
\hline & Medium (2) & $\begin{array}{l}\text { Full accessibility and some connectivity that further } \\
\text { enhanced movement }\end{array}$ \\
\hline & Advance (3) & $\begin{array}{l}\text { Full accessibility and full connectivity together with an } \\
\text { efficient traffic management system }\end{array}$ \\
\hline & State of the Art (4) & $\begin{array}{l}\text { Full accessibility and full connectivity together with a } \\
\text { sustainable traffic management system }\end{array}$ \\
\hline \multirow[t]{4}{*}{ Smart Environment } & Basic (1) & Provisions for safe and clean environment \\
\hline & Medium (2) & Protection of the environment \\
\hline & Advance (3) & $\begin{array}{l}\text { Enhancement via green technology in the environmental } \\
\text { management system }\end{array}$ \\
\hline & State of the Art (4) & $\begin{array}{l}\text { Usage of ICT in the sustainable environmental } \\
\text { management }\end{array}$ \\
\hline \multirow[t]{4}{*}{ Smart Living } & Basic (1) & $\begin{array}{l}\text { Provision of communal amenities and cohesive social } \\
\text { environment }\end{array}$ \\
\hline & Medium (2) & $\begin{array}{l}\text { Provision of extensive communal amenities and } \\
\text { cohesive social environment }\end{array}$ \\
\hline & Advance (3) & $\begin{array}{l}\text { Availability of varieties and options for global communal } \\
\text { amenities with cohesive social and living environment }\end{array}$ \\
\hline & State of the Art (4) & $\begin{array}{l}\text { Creation of comprehensive global communal amenities } \\
\text { with cohesive and integrated social and living } \\
\text { environment towards community well-being. }\end{array}$ \\
\hline
\end{tabular}


Yasmin Mohd Adnan, Hasniyati hamzah, Melasutra Md Dali, Md Nasir Daud \& Anuar Alias

An Initiative Based Assessment Framework for Smart City

\section{THE CONTEXT}

Seoul, Singapore and Iskandar were selected as case studies based on commonality of several factors including culture, socio-economy, political, geography and city functions.

\section{Case 1: Seoul}

Seoul is the capital and largest metropolis of South Korea. It has a population of an estimated of 10.04 million in 2013. The population of Seoul in 2013 is estimated at 10.44 million (World Population Review, 2016). In 2013, the city government announced the city's new vision for 2030 through the 2030 Seoul Plan. It presents measures for realizing the city's long-term vision, namely, a happy city for citizen based on communication and consideration, focusing on the achievement of 'five major key issues.' In terms of the city's spatial development, it also involves significant reforms of traditional approaches (Seoul Metropolitan Government, 2015). The 'Smart Seoul 2015' and Korea Research Institute for Human Settlements (2013) reports provided the conceptual underpinnings of Smart Seoul, the use of smart technologies and mobile-web applications to provide citizen-centric services and the role of technical standards as the precondition for smart city functionality (ITU, 2013). The current initiatives are mainly implemented and monitored by the Seoul Metropolitan Government.

\section{Case 2: Singapore}

Singapore is one of the world's major commercial hubs, with one of the busiest ports and the fourth-biggest financial centre. Singapore's total population was 5.54 million as of June 2015 with 1.63 million non-resident populations (Singapore Department of Statistic, 2015).

Within the Smart City context, it has the vision of transforming Singapore by building the World's first Smart Nation by harnessing technology to the fullest with the aim of improving the lives of citizen, creating more opportunities, and building stronger communities.

In order to be a smart city, Infocomm Development Authority of Singapore (IDA) has been established to develop information technology and telecommunications within Singapore with a view to serve citizen of all ages and companies of all sizes (Infocomm Development Authority of Singapore, 2015). IDA does this by actively supporting the growth of innovative technology companies and start-ups in Singapore, working with leading global IT companies as well as developing excellent information technology and telecommunications infrastructure, policies and capabilities for Singapore. 
PLANNING MALAYSIA

Sustainable Urban Development

\section{Case 3: Iskandar Malaysia}

The vision of Iskandar Malaysia is that of 'Strong and Sustainable Metropolis of International Standing'. In 2012, Iskandar Malaysia was declared as a pilot Smart City project for Malaysia (IRDA, 2013). Based on economic opportunities, the Smart City initiative for Iskandar Malaysia was endorsed by the government in the Global Science and Innovation Advisory Council in May 2012. The rationale for Smart City agenda was five-pronged; (i) Induces multiplier effect for economic growth and job creation nation-wide towards achieving a better lifestyle (ii) Alignment with initiatives listed in the 24 approved and endorsed blueprint (iii) Alignment with other on-going projects and initiatives in Iskandar Malaysia (iv) An easier and more efficient lifestyle and business environment based on technology (v) Creates high motivation towards achieving Iskandar Malaysia's vision - Strong and Sustainable Metropolis of International Standing (IRDA, 2015).

Iskandar Malaysia was chosen to pioneer the Smart City movement in the following areas

1. Developing a National Framework for nationwide implementation.

2. Realizing policy objectives related to ICT applications and Green Technologies.

3. Developing sustainable implementable model for industry driven approach.

4. Identifying and recommending required enabling issues and related success factors for sustainability of the programme.

5. Identifying ongoing and new locations and early win projects.

6. Addressing local capability building.

The Smart City framework for Iskandar Malaysia is based on the three main dimensions of sustainable development, namely economy, environment and social. From these basic sustainable development dimensions, six dimensions were adopted for Iskandar Malaysia Smart City. From the fieldwork, it was revealed by Iskandar Malaysia Comprehensive Development Plan II (CDP II) that the six dimensions adopted by Iskandar Malaysia Smart City are adapted from the model by Giffinger et.al. (2007).

\section{FINDINGS AND DISCUSSION}

Through the examination of documents and observations of the initiatives at the respective cities as well as the official reports prepared by the respective authorities overseeing the smart city movement, these sources provided the information that portrayed the current city development under the six (6) dimensions. Thus, the level of achievement under each dimension for each dimension is determined as shown in Table 2 below. 
Yasmin Mohd Adnan, Hasniyati hamzah, Melasutra Md Dali, Md Nasir Daud \& Anuar Alias

An Initiative Based Assessment Framework for Smart City

Table 2: Level of Initiatives Provision for case studies

\begin{tabular}{ccccccc}
\hline & $\begin{array}{c}\text { Smart } \\
\text { Governance }\end{array}$ & $\begin{array}{c}\text { Smart } \\
\text { Economy }\end{array}$ & $\begin{array}{c}\text { Smart } \\
\text { Mobility }\end{array}$ & $\begin{array}{c}\text { Smart } \\
\text { Living }\end{array}$ & $\begin{array}{c}\text { Smart } \\
\text { People }\end{array}$ & $\begin{array}{c}\text { Smart } \\
\text { Environment }\end{array}$ \\
\hline Seoul & 4 & 3 & 4 & 3 & 4 & 3 \\
Singapore & 4 & 4 & 4 & 4 & 4 & 4 \\
Iskandar & 3 & 2 & 2 & 2 & 2 & 3 \\
\hline
\end{tabular}

Generally, all 3 cities showed smart city dimensions above the 'medium' scale. This means that all the cities surpassed the basic provision of smart cities initiatives. In terms of Smart Governance, Seoul and Singapore indicated 'State of the Art' levels of achievement whereas Iskandar showed an Advanced level of smart governance provision. In terms of Smart Mobility and Smart People, Seoul and Singapore showed 'State of the Art' provisions compared to Iskandar which achieved Medium level. For Smart Environment and Smart Living, Singapore led in the provision 'State of the Art' level followed by Seoul (Advanced level) and Iskandar (Medium level). Finally, for Smart Economy, Singapore showed its leadership ('State of the Art' level) whilst Seoul and Iskandar only achieved Advanced level.

It is found that Singapore and Seoul lead when it comes to the provision of Smart City initiatives in almost all Smart City dimensions. It is evident that Singapore outperforms all other cities in this respect, scoring 'State of the Art' achievement level on all the dimensions. Seoul follows, with comparable strengths on all dimensions except smart economy and smart people. When comparisons are made to the level of achievements for the initiatives under the six (6) Smart City dimensions, Iskandar Malaysia may not achieve the high level of provision as compared to the more developed cities.

The results of the determination of the level of provision is then plotted on a radar chart and is graphically shown as in Figure 1 below. 


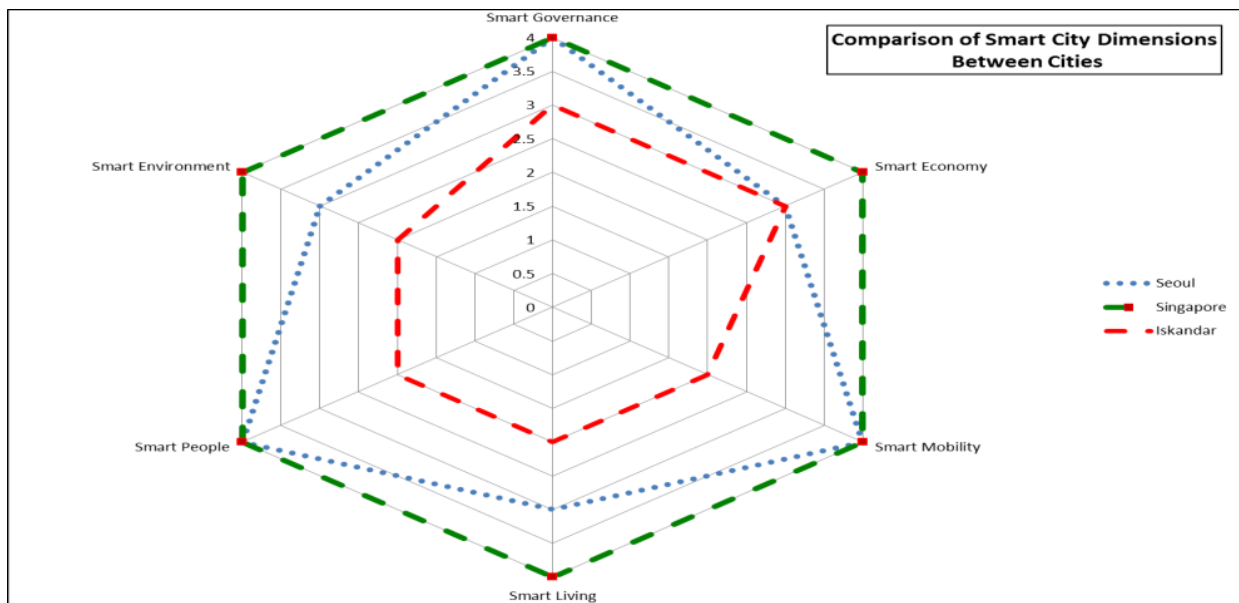

Figure 1: Radar Chart Comparing Smart City Dimensions between cities

It must be understood that the above radar chart represents a visual reflection of the selected cities at 'first instance' i.e. without considering the prevalent aspects that may have influenced the cities' development in the past. Each city was developed according to the visions of the city management which could be shaped by the countries' national agenda.

\section{CONCLUSION}

The mainstream assessment framework for smart city initiatives has proved problematic to use because of its data requirements. Non-availability and poor quality are data issues that hinder effective and efficient assessment of city smartness. This paper has proposed a simpler approach (a modification of Giffinger's) based on qualitative assessment of initiatives data. To ensure the reliability of this alternative framework, multiple sources have been relied on. The multiplicity of sources promotes a high degree of triangulation on the data. In an exercise to compare city smartness performance, the alternative framework was deployed to assess three cities within the Asia Pacific region namely Seoul, Singapore and Iskandar Malaysia. As the outcome, Singapore emerged as the Smart City leader followed closely by Seoul. Iskandar Malaysia, which started Smart City initiatives more recently, has some way to go to close the gap.

This research contributes to the Smart City literature by introducing an alternative framework for Smart City assessment. The proposed heuristic framework eliminates the requirement for large volume of baseline data that can be almost impossible to obtain for various reasons. Therefore, this proposed model enables a simultaneous assessment of many cities at once. 
Yasmin Mohd Adnan, Hasniyati hamzah, Melasutra Md Dali, Md Nasir Daud \& Anuar Alias

An Initiative Based Assessment Framework for Smart City

\section{ACKNOWLEDGEMENT}

The authors would like to acknowledge financial assistance from National Property Coordinator, Ministry of Finance under research grant ref. NAPREC (R\&D) $9 / 13$ in undertaking this research.

\section{REFERENCES}

Caragliu, A., Del Bo, C. \& Nijkamp, P. (2009).Smart cities in Europe. Proceedings of the 3rd Central European Conference in Regional Science. Košice, Slovak Republic, Oct 79. Retrieved from: http://www.cers.tuke.sk/cers 2009/PDF/01_03_Nijkamp.pdf.

Carli, R., Dotoli, M., Pellegrino, R. \& Ranieri, L. (2013). Measuring and managing the smartness of cities: A Framework for classifying performance indicators, Proceedings of the 2013 IEEE International Conference on Systems, Man, and Cybernetics.

Giffinger, R., Fertner, C., Kramar, H., Kalasek, R., Pichler- Milanovi, N. \& Meijers, E. (2007). Smart Cities: Ranking of European Medium-Sized Cities. Vienna: Centre of Regional Science (SRF), Vienna University of Technology.

IRDA. (2015). Iskandar Regional Development Authority Website. Retrieved from http://www.irda.com.my/

IRDA. (2013). IRDA Annual Report.

Info-communications Development Authority of Singapore (IDA). Retrieved from: https://www.ida.gov.sg

ITU (2013). Smart Cities Seoul: a Case Study. In ITU-T Technology Watch Report, Retrieved from: http://www.itu.int.

Korea Research Institute for Human Settlements. (2013). Smart City; A Primer on Korean Planning and Policy. KRIHS

Lombardi, P., Giordano, S., Farouh, H. \& Yousef, W. (2012). Modelling the smart city performance, Innovation: The European Journal of Social Science Research. 25(2), 137-149.

Neirotti, P., De Marco, A., Cagliano, A. C., Mangano, G. \& Scorrano, F. (2014). Current trends in Smart City initiatives: Some stylised facts. Cities, 38, 25-36

Schaffers, H., Komninos, N. \& Pallot, M. (2012). Smart cities as innovation ecosystems sustained by the future internet. Retrieved from: http://www.fireball4smartcities.eu/wp-content/uploads/2012/05/FIREBALLWhite-Paper-Final2.pdf

Seoul Metropolitan Government (2015). Retrieved from: http://english.seoul.go.kr

World Population Review (2016). Seoul Population 2016. Retrieved from: http://worldpopulationreview.com/world-cities/seoul-population

Singapore Department of Statistics. (2015). Statistics Singapore - Latest Data - Population \& Land Area (Mid-Year Estimates). Retrieved from: http://www.singstat.gov.sg/statistics

Vanolo, A. (2014). Smart mentality: The Smart City as disciplinary strategy. Urban Studies. 51(1), 883-898.

Yanrong, K., Lei, Z., Cai, C., Yuming, G., Hao, L., Ying, C. \& Hart, T. (2014). Comparative Study of Smart Cities in Europe and China. EU-China Policy Dialogues Support Facility II: Ministry of Industry and Information Technology (MIIT) and China Academy of Telecommunications Research (CATR). 